\title{
LAS MUCHACHAS MAYAS DE YAXCABÁ, YUCATÁN
}

\author{
Young Woman Maya in Yaxcabá, Yucatan
}

Maya Lorena Pérez-Ruiz

Resumen: El tema de este artículo es el significado de ser mujer y ser joven en la cultura maya de Yucatán, México. Se presentan testimonios de muchachas de bachillerato del pueblo de Yaxcabá con el objetivo de conocer lo que para ellas significa ser mujer joven. Sus percepciones y sus proyectos de futuro se enmarcan en un campo de conflicto, en el que existe un enfrentamiento entre jóvenes y adultos para mantener o transformar los significados y las prácticas de ser joven.

Palabras clave: jóvenes, mayas, mujeres, brecha generacional.

Abstract: The subject of this article is what does being a woman and being young mean in Yucatec Mayan culture in Mexico. Testimonies of high school girls from the village of Yaxcabá are presented to show how these girls define their role as young women within their culture. Their perceptions and future projects, often in conflict with those of their elders, are part of a process of transformation of societal values and practice in this Mayan region.

Keywords: youth, Mayas, women, generation gap.

Maya Lorena Pérez Ruiz. Doctora en Ciencias Antropológicas por la Universidad Autónoma Metropolitana, Unidad Iztapalapa. Profesorainvestigadora en el Instituto Nacional de Antropología e Historia, México. Temas de especialización: pueblos indígenas y sus relaciones con el Estado, con énfasis en los procesos identitarios y organizativos; juventudes indígenas y sus problemáticas étnicas, de género, de generación y de clase. Correo electrónico: mayaluum@gmail.com.
Enviado a dictamen: 11 de abril de 2016. Aprobación: 13 de septiembre de 2016. Revisiones: 2. 


\section{Puntos de partida}

E ste trabajo se apoya en la historia, la lingüística y la etnografía, así como en un cuestionario levantado en el año 2010 dirigido a muchachas de bachillerato del poblado de Yaxcabá, Yucatán, en el que se les preguntó lo que para ellas significaba ser joven, así como sobre lo que pensaban del amor, el noviazgo, el matrimonio concertado por los padres y su futuro. Se trató de un cuestionario de preguntas abiertas que ellas contestaron desde su narrativa y léxico propios. Para ubicar desde qué posición social escribían, se les solicitó que especificaran su edad, su religión, si tenían apellidos mayas y si su familia cultivaba milpa o no.

Analizar las respuestas de las muchachas, desde la intersección entre lo que significa ser mujer, ser joven y pertenecer a un pueblo de origen maya, ha constituido un reto metodológico porque para ello se debieron recuperar los referentes históricos, étnicos, lingüísticos, familiares, sociales y culturales que intervienen en la construcción social tanto del género, como de la juventud. Se consideraron insuficientes para esta labor los criterios centrados sólo en la edad que se utilizan en los censos nacionales de población y en los organismos e instituciones nacionales e internacionales. Bajo la experiencia de lo que sucede en varias partes de América Latina (Pérez Ruiz, 2008), se creyó necesario partir de las concepciones emic brindadas por la población de origen maya para, desde ellas, analizar las continuidades y las transformaciones de lo que significa ser joven. De esta forma, en este trabajo se asume que "ser joven" es una categoría de clasificación (Pérez Ruiz, 2015) producto de una construcción social, relativa, histórica e ilegible en sí misma ya que no se trata de un "descriptor universal" (Reguillo, 2000) y, en cambio, forma parte de las estrategias de producción y reproducción de las sociedades, en este caso de aquellas que organizan las diferencias sociales relativas al tránsito de la infancia a lo que se supone que es la adultez (Feixa y González, 2005). Así, el ser joven, como categoría de clasificación social, se construye desde referentes culturales específicos que se expresan en las peculiaridades que adquiere la lucha por el reconocimiento para dotar de significado a las categorías orientadas a ordenar las diferencias sociales (Giménez, 2003). La peculiaridad de "ser joven" en cada contexto expresa, entonces, los procesos de reconocimiento, identificación y clasificación que se establecen para otorgar atributos, características, valores y posiciones sociales específicas a los grupos sociales en que se organiza el tránsito de una etapa a otra del ciclo de vida. La posición relativa de cada grupo establece su forma de acceso a los recursos sociales, así como la manera en que deben participar sus miembros en la toma de decisiones familiares y sociales, entre otros aspectos. Lo anterior supone la necesaria validación social de las marcas y cualidades de identificación/clasificación de cada grupo, las cuales se establecen en contextos de asimetría y de relaciones de poder entre generaciones en medio del conflicto y la negociación, por lo que están en permanente proceso de confirmación, actualización y transformación. Así, el ser joven, en el contexto de la cultura maya yucateca y en el conjunto del ciclo de vida, se complementa con las categorías "ser niño" y "ser adulto", al tiempo que posee cualidades específicas con las que se diferencia de éstas; además, los atributos y valores que caracterizan a los jóvenes se están actualizando y modificando constantemente como resultado de la interacción social, incluso con actores externos con los que interactúan los pobladores de origen maya, en un proceso constante de adecuación a las nuevas condiciones históricas y sociales. Por otra parte, asumir aquello que la población maya considera "ser joven" es dar voz a los actores para no privilegiar la perspectiva del investigador.

El otro punto de partida se relaciona con lo que significa "ser mujer", ya que desde Margaret Mead, al finalizar la segunda década del siglo XX, se insiste en que la construcción de los géneros es cultural, por lo que puede variar según los contextos (Mead, 1970, 1979). Con un principio similar, diversos autores enfatizan el papel de la historia, la cultura, y las relaciones sociales y étnicas en su construcción (Báez-Jorge, 1975; Oehmichen, 2005; Urteaga, 2008). Así, el género en una sociedad determinada expresa, por ejemplo, las percepciones sobre las diferencias biológicas, sexuales y ontológicas entre hombres y mujeres, e 
incluso con las de un tercer o cuarto género, para definir sus cualidades y regular la interacción social. La construcción y representación social del género, de los géneros, se construye siempre en contextos histórica y culturalmente situados en el espacio y el tiempo, y en interacción entre instituciones y actores diversos. Intervienen operaciones de reconocimiento entre individuos y grupos sociales (Giménez, 2003), así como procesos de categorización en los que se ponen en juego relaciones de poder y procesos de valoración y jerarquización, con la consecuente lucha por el control de los recursos —económicos, culturales y simbólicos-, de las instituciones desde las cuales se legitiman los géneros - la familia, la religión, la escuela y los medios masivos de comunicación social, entre otras- y de las prácticas sociales que las acompañan (Conway, Bourquw y Scott, 2000; Kay Vaughan, 2002; Oehmichen, 1999; Ortner y Whitehead, 1991; Ramos, 1991; Scott, 1996).

\section{La construcción de "ser mujer" y "ser joven" entre los mayas de Yucatán}

Actualmente en Yucatán se discute sobre el tipo de construcción histórica que se ha hecho en torno a la mujer maya. Algunas investigadoras se han interesado por hacer visible a la mujer maya (De la Garza, 2003; Rosado, 1999a; Santana, 1999), y en ese contexto se ha buscado recuperar su papel como actora en el mundo simbólico y político, en la producción y en la vida social y familiar. Para ello algunas autoras han reelaborado el principio de dualidad, ${ }^{2}$ fundamento de la cosmogonía maya, dando un sentido de complementariedad a la relación entre hombres y mujeres, y no ya de oposición, como lo han presentado la mayoría de los mayistas. Por ejemplo, Santana Rivas (1999: 43) dice que: “[...] la mujer prehispánica era más valorizada y tenía más libertad de acción y participación”, de modo que la "subordinación, desigualdad, inferioridad, fue un concepto que no se conocía y fue importado por el colonialismo". Así, para esta autora, lo que para los mayas era complementario, los conquistadores españoles lo tradujeron como oposición, desigualdad einferioridad. Sustenta su hipótesis en datos arqueológicos y en la cosmología maya. Dice, por ejemplo, que Itzamná era el dios del sol e Ixchel era la diosa de la luna: el primero era protector y la segunda la diosa de los torrentes e inundaciones. Respecto al parentesco, argumenta que existían tanto una descendencia matrilineal, como otra patrilineal: la primera era necesaria para establecer vínculos con las deidades y la segunda era útil para regular el parentesco necesario para la vida social. Además, le importa señalar que no todas las mujeres eran iguales, de forma que las del común eran productoras y reproductoras, mientras que las de clases altas eran guerreras, lideresas, sacerdotisas, maestras, parteras y curanderas, pero todas ellas eran actoras sustantivas en la vida social, política y religiosa de los mayas. Otros autores también señalan la importancia de recordar que, en el momento de la Conquista, en Yucatán los pobladores de origen maya no formaban bloques sociales homogéneos. Se diferenciaban por su adscripción a algún señorío - tipúes, cehaches, itzaes, mopanes y lacandones- y por ser del común - macehuales - o de las élites gobernantes - chuntanes- (Bracamonte y Solís, 1996), de lo que puede inferirse que la situación de las mujeres variaba de acuerdo con su posición social.

Otra autora importante en la tarea de hacer visible a la mujer maya ha sido Rosado Rosado (1999a, 1999b), quien se ha propuesto romper la visión de "víctima" que según ella prima en los acercamientos latinoamericanos en torno a la mujer indígena. Para construir una visión alternativa a esa perspectiva victimaria revisó la etnografía del siglo XX sobre los mayas — Redfield, Villa Rojas, Hansen, Morris, Trujillo, Elmendorf, Rivera y Thompson-, para desde allí reconstruir lo que fue la mujer maya durante las primeras décadas del siglo XX. Esta autora encuentra que los etnógrafos mencionados, si bien en sus estudios no reportan que existiera igualdad en las relaciones entre los géneros, no llegan a mostrar una total subordinación y ausencia de poder o prestigio por parte de la mujer. Además, tampoco registran espacios sociales totalmente segmentados para hombres y mujeres. Y, si bien muestran que las mujeres participan en la reproducción y la organización de la familia, evidencian que lo hacen también en la economía familiar, la política y el trabajo asalariado, 
aunque mediadas por el prestigioso papel de ser madre. Cabe decir, sin embargo, que esta autora, en su revisión de la etnografía producida en Yucatán durante el siglo XX, también corrobora la preponderancia de la autoridad generacional sobre la de género, de forma que concluye señalando que la complementariedad entre hombres y mujeres no implica que se trate de sociedades no jerarquizadas. Esto, por el contrario, demuestra que, mientras más tradicional es un grupo social, más verticales y rígidas son las relaciones de autoridad, de forma que los hombres están por encima de las mujeres y los ancianos por encima de los jóvenes. A la luz de la información analizada por esta autora no se logra construir una respuesta contundente sobre si lo que ha imperado en las relaciones entre hombres y mujeres de origen maya ha sido la complementariedad o la desigualdad.

Para abonar al conocimiento de lo que ha sido la situación de las mujeres mayas, cabe traer a la memoria a Diego de Landa, fraile que llegó a la Península de Yucatán en 1549. Éste, en su libro Relación de las cosas de Yucatán(De Landa, 2001), ofrece elementos para explicar las diferencias sustanciales de posición y poder que existían en el momento de la Conquista entre hombres y mujeres del común. Un elemento fundamental era el sistema de herencia que privilegiaba a los hijos, a los hermanos o incluso a un tutor, antes que a las hijas, hermanas o esposas. Otro elemento era el control social que se ejercía sobre la sexualidad, que era diferente para hombres y mujeres, ya que prevalecía el derecho del marido sobre la vida sexual de su esposa, situación que Álvarez (1997) explica al analizar cómo en el maya yucateco colonial se empleaba el mismo verbo (al) para "parir", en relación con el alumbramiento de la mujer, y para la producción de la tierra, lo que muestra lingüísticamente cómo, después del matrimonio, la mujer pasaba a ser propiedad del esposo, igual que la tierra. Incluso cuando una mujer perdía su capacidad reproductora, pasaba a ser dependiente económica y socialmente de un hombre, trátese de su marido, su hijo o un hermano. El control sobre el cuerpo y la sexualidad de las mujeres comprendía tanto a las solteras como a las casadas, aunque difería del que se ejercía sobre las esclavas, las huérfanas y las viudas, que eran como "terrenos sin dueño" y que llegaban a prestar "sus servicios" sexuales a los jóvenes varones. Con un sentido similar, De Landa (2001) menciona que los jóvenes mayas recibían una educación particular, confinados en una escuela especial donde recibían la visita de mujeres para calmar sus ímpetus sexuales. No explica, sin embargo, si esos sitios eran sólo para los varones con cierta jerarquía social.

Respecto a los jóvenes, hombres y mujeres, Diego de Landa (2001) menciona los ritos asociados con la pubertad y muestra las advertencias y cuidados que giraban en torno a lo que debía ser su comportamiento, así como los controles sociales sobre la sexualidad. Para las muchachas era importante conservar su virginidad y se controlaba la sexualidad de las casadas mediante la penalización de la infidelidad. Una forma de control era la murmuración, a lo que se agregaba el castigo en casos de adulterio. En la amplia descripción que De Landa hace sobre los ritos de la pubertad, que él llamó bautizo, se advierten las normas de la obediencia hacia los mayores que debían cumplir los jóvenes. Respecto al matrimonio, registra que éste era arreglado por los padres y no mediante la libre elección de los contrayentes. El padre del novio debía dar una dote a la familia de la novia, y era costumbre que la nueva pareja se quedara a vivir en la casa de los padres de la recién casada trabajando hasta por seis años para beneficio de su suegro.

De la Garza (2003), en diálogo con De Landa y otros autores, también afirma que, en el momento de la Conquista, entre las mujeres mayas había jerarquías, y a las que se refería De Landa era a las del pueblo, y no a las de posición alta que aparecen plasmadas en códices y pinturas. Las almehenoob son las destacadas en los registros. Álvarez (1997) desde la lengua maya explica también la situación desigual de las mujeres según su posición social. Entre las clases altas el matrimonio estaba determinado directamente por los requisitos sociales y de prestigio. La alianza matrimonial debía permitir consolidar el ascenso social mediante el cumplimiento de compromisos públicos y religiosos, y de tal unión se esperaban hijos para continuar los 
linajes. Esta situación variaba para las mujeres de las clases inferiores, como se ha visto antes, a quienes se les equiparaba con las formas de posesión de la tierra.

Después de la Conquista, los evangelizadores centraron gran parte de su interés en el cuerpo humano, sus funciones y sus manifestaciones, ya que para ellos no era sólo el asiento del alma, sino también el vehículo de sus pasiones, de la ejecución del pecado. Era necesario domesticarlo e incorporarlo al universo de lo propio, y combatieron el adulterio, la poligamia, el amancebamiento y la masturbación, entre otros aspectos (Ruz, 2004). Impusieron así un orden social con su concepción del cuerpo, el alma y la conyugalidad. Con la Colonia las escuelas de doctrina eran las vías para esa resocialización. A los hombres se les prohibió vestirse de mujeres para participar en algunas fiestas y todo aquello que los incitara al pecado y la lujuria. A las mujeres se les obligó a cubrirse con una camisa larga, ohipil, y se les inculcó con nuevos bríos y castigos la virginidad, la castidad y la fidelidad (Santana, 1999).

Las niñas que estaban a punto de ser muchachas, a partir de los once años, tenían prohibido andar solas en las calles, incluso para ir a la iglesia. Ya desde los doce o trece años se consideró que eran aptas para el matrimonio, un cambio impuesto ya que, según De Landa (2001), antes lo hacían alrededor de los veinte años. Para Santana Rivas (1999) este cambio se debió a la necesidad de los evangelizadores, conquistadores y encomenderos de agilizar la reproducción de la mano de obra. Además, eso les traía beneficios económicos ante el mayor número de bodas y bautizos y por la pronta catequización de las nuevas generaciones de mayas. Otra razón, no menos poderosa, fue la de aumentar el número de jefes de familia para recaudar impuestos. Todo lo anterior demuestra cómo, desde entonces, el ser joven y el dejar de serlo estaba condicionado no sólo por factores biológicos y culturales, sino también por intereses económicos y políticos, asociados, entre otras cosas, a la dominación y la explotación (Pérez Ruiz, 2015).

De Landa (2001) aporta información también sobre la existencia de los jóvenes entre los antiguos mayas. Su descripción del rito de paso que llamó "bautizo" muestra algunas prescripciones sociales que los norman, como la abstinencia sexual, el pecado del "tocamiento" y la capacidad de los padres para acordar su matrimonio. Asimismo, deja ver que ser joven, en hombres y mujeres, denotaba una etapa de transición y formación que concluía con el matrimonio, cuya concepción y normatividad se regía por las ideas del cosmos, la vida, la muerte y el cuerpo que tenían los pueblos mesoamericanos.

Álvarez (1997) corrobora también la presencia prehispánica de los jóvenes, y en el Diccionario etnolingüístico del idioma maya yucateco colonial consigna un amplio abanico de palabras para referirse a éstos. La forma de nombrarlos hace alusión a esa transitoriedad de la que habla De Landa. Por ejemplo: yihuinic-il se traduce como "entrar en edad, hombre rudo"; ichan-cil se traduce como "fructificar, dar fruto", y cuxol se traduce como "juicioso, racional, prudente, entendido, discreto". Para mencionar a la juventud se consignan las palabras celem-al y celem-il, que se corresponden con la edad o la mocedad de la tierra cuando tiene fuerza y vigor. En cambio, ch' up il-il significa juventud para la mujer. Para las jóvenes, los términos se refieren a sus cambios físicos, a su madurez y a su preparación para el matrimonio: ix lokbayen-tal se traduce como "llegar la mujer a la edad de la pubertad"; box tan yem significa "calabacita tiene" y se traduce como "mozuela a quien le crece el pecho", mientras que zuhuypaal significa "virgen muchacha", y ah top' zakab se traduce como "doncella casadera” (Álvarez, 1997: 255-256).

En la actualidad, si bien algunos de esos elementos han desaparecido, como el rito que marcaba el tránsito de la niñez a la juventud, otros han permanecido y se han actualizado a lo largo del tiempo. Por ejemplo, se conservan algunas nociones en lengua maya para nombrar a los muchachos y muchachas — que lo son, luego de la niñez, en tanto no se casen-, y por mucho tiempo se mantuvo la costumbre de que los padres debían escoger a la pareja de los hijos —estuvo vigente durante la primera parte del siglo XX, aunque hoy es casi inexistente- - Además, persisten las prácticas encaminadas a vigilar la virginidad y la sexualidad de las mujeres, solteras y casadas. Con los ajustes propios 
de la concepción patriarcal de la organización social impuesta por los hispanos, las mujeres siguen siendo quienes se trasladan al ámbito familiar del esposo porque la pareja recién constituida se supone que debe habitar en la casa de los padres del esposo durante los primeros años del matrimonio, y no de la familia de la esposa, como registra De Landa (2001) para antes de la Conquista. Estos son los aspectos sobre los cuales las muchachas mayas contemporáneas fincan sus demandas de cambio.

\section{Hacerse mujer entre los mayas del Yucatán contemporáneo}

En Yaxcabá ser mujer se construye desde el nacimiento, y su posición y su valor se refuerzan durante todo el ciclo de vida. Cuando va a nacer un nuevo miembro de la familia y se recurre a la partera, ésta cobrará menos si se trata de una niña, ya que se considera que los hijos varones valen más, al ser fundamentales para lograr un buen equilibrio entre productores y consumidores, además de que son ellos quienes garantizarán la continuidad de una familia, de un apellido. Por su parte, las mujeres al casarse pasarán a formar parte del grupo familiar del esposo. El menor valor de las mujeres se expresa, por ejemplo, en la costumbre de servir mayores raciones de comida a los varones, así como en dar prioridad a los hombres para que estudien (Pérez Ruiz, 1983, 2015). En dicha percepción se ignora el valor de las mujeres para la reproducción de la familia - cuidado de la casa y de los niños, tareas domésticas, etcétera-, así como su participación activa en la conservación de los germoplasmas, en la producción familiar y en la comercialización, por ejemplo, de animales de solar — gallinas y pavos, principalmente-, hortalizas, plantas medicinales, frutales, hamacas y bordados, entre otros productos.

El hetzmek es otro momento importante para la construcción del género. Se trata de una ceremonia en la que se carga a horcajadas a los pequeños por primera vez y se les enseña simbólicamente el tipo de trabajo que deben aprender. Con el apoyo de una madrina y un rezador, se realiza esta ceremonia para las niñas cuando tienen tres meses, porque tres piedras tiene el fogón de la cocina. Durante el acto se les coloca lo propio para que aprendan a ser amas de casa y a bordar, aunque es posible que se les ponga en las manos un lápiz y un cuaderno para que también vayan a la escuela. Sobre tales referentes se les educa, socializarán y trabajarán.

Construirse como mujer incluye formas especiales para el cuidado del cuerpo y la alimentación que influirán en su salud y su capacidad reproductiva (Güemes, 2000). Por ejemplo, durante la menstruación - la sangre es caliente - una muchacha no debe comer alimentos fríos y tiene restricciones para comer limón, naranja y jícama, además de que no debe exponerse a la lluvia o de lo contrario puede enfermarse de pasmo, quedar estéril y hasta morir. Además, durante el período menstrual las mujeres en general no pueden caminar entre la milpa y los chilares ya que dañarán los cultivos. De igual manera, han de participar de forma peculiar en la división del trabajo, así como en las tareas y responsabilidades en las ceremonias y las fiestas. Por ejemplo, las mujeres cuidan el altar doméstico y están a cargo de las misas y las novenas, mientras que contribuyen sólo colateralmente en las ceremonias asociadas con las deidades que habitan los espacios masculinos como el monte y las milpas. Así, ellas serán las que pondrán el nixtamal y harán las tortillas para las ceremonias de petición de lluvias, pero jamás podrán entrar al espacio ceremonial donde oficia el hmen o sacerdote maya, lo que da como resultado habilidades y conocimientos diferenciados entre hombres y mujeres (Pérez Ruiz, 1983, 2015).

En cuanto a un tercer o cuarto género, se carece de información empírica al respecto, aunque se sabe de su existencia por referencias lingüísticas que dan cuenta de hombres afeminados y de mujeres que actuaban como hombres. Por ejemplo, Álvarez (1997: 63-65) consigna los siguientes términos entre los mayas coloniales: pak-alaay, con el significado de pecar una mujer con otra como si una fuese varón, ych'up-laluinic, como hombre afeminado y cobarde; sin embargo, para los mayas contemporáneos el Diccionario básico españolmaya-español(1992) no consigna ningún término para las mujeres homosexuales. Por su parte, el Diccionario 
maya-español (2001) consigna, entre otros, ch'upalol como hombre afeminado, $x$-ch'upulxib da cuenta de un hermafrodita, mujer, y xbil $x$-ch'up es una mujer con carácter de hombre. En todo caso, queda éste como un aspecto por investigar.

\section{Para ser muchacha}

En la actualidad, en lengua maya perduran ciertas palabras para nombrar a las jóvenes. Por ejemplo, el Diccionario básico español-maya-español (1992) consigna que xchu'úupal significa muchacha, mientras ch'úupal y (x) lo'obayan señalan lo joven femenino. Por su parte, en Yaxcabá de forma coloquial se dice chu'palech para nombrar a las muchachas, lo que significa que están en peligro a la vez que generan peligro, en alusión a su sexualidad, a su menstruación, a su capacidad reproductiva y a las normas que deben seguir. Según el lingüista Fidencio Briseño Chel, al nombrar a las muchachas $(x)$ lo'obayan se les asocia con daño, con que están dañadas porque han menstruado, ${ }^{3}$ en tanto que a los jóvenes, al llamarles táankelem, se les reconoce como "la cara de la fuerza" en relación con el poder masculino predominante.

En ese marco cultural, el ser muchacha se inicia con la pubertad, aproximadamente a los once o doce años. Cuando éstas usan hipil, es el momento en que deben ponerse abajo el fustán - fondo con encaje blanco-. Para ellas inicia entonces una etapa en la que se acentúa la vigilancia sobre su comportamiento, de modo que ya no es bien visto que salgan solas a la calle y la familia hace lo posible para que su comportamiento no genere chismes. También se cuida su virginidad y se controla su sexualidad para que no se embaracen antes del matrimonio. Además, se observan prácticas en la alimentación y el cuidado del cuerpo para no alterar negativamente el ciclo menstrual y que se provoquen enfermedades que afecten en el futuro su capacidad de reproducción. Cuando inicia la pubertad ellas ya saben realizar las actividades del hogar, han aprendido todo lo relacionado con el cuidado del huerto familiar, el urdido de hamacas y la costura, además de que participan en el cuidado del altar familiar y están al tanto de los compromisos sociales que se tienen con la familia ampliada, con los vecinos y con la Iglesia. El primer indicador de que empiezan a ser muchachas es el crecimiento de los pechos — como calabacitas tiernas- y las caderas, hasta que alrededor de los quince o dieciséis años ya están "maduras" y listas para el matrimonio. En años recientes, la "fiesta de quince años" para las muchachas, al estilo de las ciudades, se ha vuelto un marcador social de la juventud y de prestigio que hace del conocimiento de todo el pueblo que una muchacha ya es apta y está disponible para casarse. En algunos grupos familiares, sin embargo, la soltería puede prolongarse hasta más allá de los veinte años, dependiendo de factores múltiples que van desde las estrategias grupales de reproducción económica, hasta el deseo de las muchachas por no casarse pronto (Pérez Ruiz, 1983, 2015).

En la cultura maya la juventud es una etapa transitoria que implica la obediencia y el respeto hacia los adultos y que termina con el matrimonio, sin importar la edad en la que éste se realice. Incluso se designa con nombres específicos a las personas que nunca llegan a casarse y que, por lo mismo, adquieren un estatus especial al no ser jóvenes, pero tampoco adultos, tema sobre el que también deben desarrollarse investigaciones específicas.

Todo lo anterior, sin embargo, se está transformando bajo la influencia de la educación escolarizada, el trabajo migratorio, las Iglesias y los medios masivos de comunicación, nuevas formas de educación y socialización que en conjuntoinfluyen en la temporalidady en las formas de vivir la juventud, en las maneras de adquirir pareja y en la consideración sobre cuál es el momento de casarse, así como en las relaciones entre jóvenes y adultos. De este modo, es cada vez más frecuente escuchar quejas acerca de que las muchachas actuales ya no son obedientes, de que son renuentes a cumplir con sus obligaciones en la casa y aceptan cada vez menos la tradición que las obligará a vivir, durante los primeros años de su matrimonio, en la casa de los padres de su esposo, donde quedarán bajo la vigilancia de sus suegras. 


\section{Dejar de ser muchacha. El noviazgo, el control de} la sexualidad y el matrimonio

En la bibliografía histórica, lingüística y etnográfica sobre los mayas de Yucatán, así como entre los testimonios orales y escritos recabados en campo en Yaxcabá, la juventud tiene un sentido transitorio que se percibe como una etapa de la vida asociada con la fertilidad, en la que se demuestran las habilidades de las muchachas para asumir la madurez y la adultez, de modo que concluye con el matrimonio sin importar la edad de los contrayentes. En "los tiempos de antes" la elección de la pareja era sobre todo un asunto de las familias, y no de preferencia de los posibles contrayentes o de amor entre ellos. Así lo consignan, para los primeros tiempos de la Colonia, De Landa (2001), Álvarez (1997) y De la Garza (2003). Este mecanismo tenía como efecto que gran parte de la responsabilidad del matrimonio recayera en los padres de ambos contrayentes, de modo que cuando había una desavenencia en la pareja, o incluso acusaciones de maltrato o de irresponsabilidad por parte del esposo, era tarea de los padres y suegros intervenir para resolverlo. ${ }^{4}$

En la actualidad, por presión de las mujeres y varones jóvenes es cada vez menos frecuente que los padres intervengan en la elección de la pareja, aunque participan abiertamente para dar formalidad a la etapa previa, llamada comúnmente "de visitar a la muchacha", que hoy comienza a considerarse como una etapa "de noviazgo" con la que se busca proteger a la muchacha. Además sigue vigente, aunque con excepciones, la costumbre de que la nueva pareja viva durante un tiempo en el solar de los padres del muchacho.

Los jóvenes actuales, aunque con restricciones, se relacionan inicialmente a través de la amistad y pueden entablar relaciones de noviazgo por su voluntad. Sin embargo, para dar seriedad a la relación el muchacho deberá pedir permiso al padre de la muchacha para "visitarla", con lo que asume un compromiso que los conducirá al matrimonio. El permiso lo otorgará el padre si le parece adecuado el solicitante, según provenga de una familia con la que tenga buenas relaciones de amistad o de parentesco ritual — compadrazgo-. Ello se debe a que los padres de los contrayentes tendrán que apoyar a la nueva familia con recursos - dinero, animales de solar, semillas, mano de obra, entre otrosy hasta con un solar para que en el futuro construyan su casa. La duración de las visitas antes del matrimonio es variable. Se han encontrado casos en que este plazo es de entre dos y cuatro años, pero en otros es más breve, y depende, por ejemplo, de la capacidad económica del muchacho y su familia, ya que ellos pagarán el vestido de la novia y los gastos de la boda. Por otra parte, se ha ido expandiendo la moda citadina de conseguir padrinos —normalmente parientes - que contribuyen a pagar el pastel, la bebida o los músicos.

El control de las mujeres, de su trabajo y de su sexualidad permanece aún durante el matrimonio, se acentúa cuando las casadas quedan bajo la vigilancia de sus suegras y cuñadas, y se torna todavía más estricto cuando el esposo sale a trabajar fuera del pueblo. ${ }^{5}$ Son innumerables los relatos sobre las difíciles relaciones entre nueras y suegras, por ejemplo, en torno a quién debe manejar el dinero del hogar o tomar las decisiones importantes. El conflicto y el excesivo control que se ejerce sobre las nueras son elementos claves para comprender por qué en la actualidad las muchachas quieren que las tradiciones cambien. Sueñan con formas diferentes de noviazgo, con escoger ellas mismas a su pareja y con tener un matrimonio en que puedan "vivir aparte", sin la presencia de los suegros.

Su rebeldía se expresa en las prácticas transformadoras que ellas están realizando para seleccionar a su pareja. Sobre todo entre quienes han salido a trabajar a la ciudad de Mérida o a la Riviera Maya, existen muchachas que toman la iniciativa para hacerse novias del muchacho que les gusta, e incluso deciden el momento para que ella y el joven elegido vivan juntos. También se observa en las escapadas de las estudiantes para pasear en la plaza con sus amigas y en sus visitas a los cibercafés y a las casas de sus compañeros de estudios para hacer tareas y trabajos escolares, así como en sus demandas para asistir a fiestas y tardeadas, antes inexistentes en el pueblo.

Hasta ahora no se ha podido encontrar un término en maya yucateco para el acto de "visitar" a la muchacha 
y formalizar una relación de noviazgo; tampoco se ha encontrado otro para consignar las relaciones de noviazgo que establecen los jóvenes libremente, lo que no necesariamente implica el compromiso de un futuro matrimonio. En este último caso se trata de un tipo de relación casual, temporal, que despierta el enojo de los adultos ya que implica en muchos casos el desprestigio de la muchacha, que ganará fama de loca, de ser poco seria y de no ser buena candidata para el matrimonio. El desprestigio será mayor si ésta ejerce por decisión propia su sexualidad y se embaraza, hecho cada vez más frecuente, con el añadido de que ahora los chicos "se fugan" a trabajar fuera para no responsabilizarse de la muchacha y de su hijo. En estos casos, la mujer, que deja de ser joven, se ve obligada a permanecer en el hogar de sus padres o abuelos, generalmente sin que pueda casarse más adelante. También puede suceder que ésta se vaya del pueblo a trabajar a la ciudad dejando a su hijo o hija bajo la responsabilidad de su familia, lo que genera una situación conflictiva ya que, aunque los padres o abuelos reciban dinero para su manutención, padecen el desprestigio, y en ocasiones sufren la rebeldía de los hijos de la mujer porque éstos se sienten abandonados y no reconocen la autoridad de quienes se quedan a cargo de ellos.

Como se verá a continuación, la idea de la individualidad, asociada con un conjunto de derechos - a divertirse, al amor, a escoger pareja, a ser feliz y a decidir sobre su vida-, es ahora importante en el imaginario de las muchachas de origen maya, lo cual influye para definir lo que para ellas significa ser joven y sus expectativas de futuro.

\section{Qué significa "ser joven" y la demanda de las muchachas de ser felices e independientes}

Para las muchachas de Yaxcabá ser joven significa una búsqueda personal frente a un mundo que se transforma bajo múltiples influencias. En el cuestionario levantado a las muchachas en el Colegio de Bachilleres del Estado de Yucatán (COBAY) en 2010, ante la pregunta de qué significa ser joven, se encontraron tres tendencias que en ocasiones se entremezclan. La primera indica que ser joven se refiere a una etapa de la vida en que se deja atrás la niñez, para entrar a otra dedicada a aprender lo necesario para alcanzar aquello que se desea ser en el futuro. Esta idea refleja una continuidad con la concepción tradicional de lo que significa ser joven en la cultura maya al estar asociada con la evolución biológica y social de los individuos, lo que sugiere que la juventud es una etapa de formación. Sin embargo, también contiene elementos de cambio ya que ese aprendizaje ahora se dirige a lograr lo que se "quiere ser en el futuro", idea que incorpora las expectativas de futuro, el deseo y el interés personal, en ocasiones dejando de lado la predeterminación de lo que se debe ser según el sexo, la edad y el papel establecido para cada miembro de una familia. La segunda tendencia, al igual que en la caracterización tradicional, hace referencia a una etapa de tránsito que necesariamente termina con el matrimonio. Finalmente, en la tercera se asocia el ser joven con la diversión, la moda, la libertad y la capacidad para disfrutar de la vida porque todo ello se acabará con el matrimonio. Esta última visión es la que mayores tensiones provoca con los adultos ya que, si bien incluye la idea de transitoriedad que caracteriza la perspectiva tradicional, se asocia con valores problemáticos para las normas de convivencia intergeneracional dado que las muchachas asumen varios derechos individuales como el derecho a poseer libertad individual, el derecho a decidir, el derecho a la diversión, el derecho a la felicidad, el derecho a decidir sobre su cuerpo y el derecho a ejercer su sexualidad. En suma, reivindican el derecho a decidir sobre su vida y su futuro, lo cual trastoca las formas de control que normalmente ejercen los adultos sobre los jóvenes. Se presentan a continuación algunos testimonios textuales de lo que significa ser joven entre las estudiantes: 6

- "Ser joven es cuando disfrutas la vida. Como quieres porque cuando estés casado no lo podrás hacer". Para ella: "A la edad de 12 años empiezas [a ser joven] tal vez hasta cuando te quedan fuerzas" (muchacha de 15 años, con un apellido maya, de padre milpero y evangélica).

- "Ser joven, es disfrutar a lo maximo lograr todo lo que quieras haciendo lo posible y por supuesto 
estudiar para salir adelante". Para ella la juventud empieza a los 14 años, y mencionó los 50 como punto final de esta etapa (muchacha de 16 años, dos apellidos mayas, su familia hace milpa y es católica).

- "Ser joven es algo muy importante por q antes de casarte ya ayas terminado de disfrutar tu vida". "A los 15 empiezas [a ser joven] y se termina asta cuando te ayas casado y tengas pareja" (muchacha de 15 años, un apellido maya, su papá hace milpa y no señaló profesar ninguna religión).

- "Ser joven es valernos por nosotros mismos en la mayor parte de las veces y saber ya lo que queremos ser en el futuro". "Se empieza a los 18 años hasta cuando nos casemos se termina la juventud" (muchacha de 16 años, dos apellidos mayas, su papá hace milpa y es católica).

La articulación de ser joven con el derecho a divertirse, a vivir el amor, a ser felices y a tomar decisiones la ejemplifican los siguientes testimonios, aunque no coinciden en todos los aspectos:

- Ser joven "es una etapa en la que nos pasan cosas maravillosas y en la que estoy viviendo ahora". Yo soy joven "porque no he cumplido los 18 o los 21 años y porque me gusta divertirme". Del futuro espera: "tener un buen trabajo y ser feliz con mi familia y las personas que quiero". Ella cree en el amor y quiere casarse. Considera que para ello el noviazgo es importante "porque empiezo a conocer más a la persona mas importante en mi vida y a ver si me va bien o no". En su pareja busca: "Que me respete, sea bueno y amable conmigo, que me quiera y que me ame y que yo sea feliz con el". Y en cambio, no aceptaría que éste: "me maltrate, que me insulte, que abuse de mi y no me respete". Ella piensa: "Que no es justo que ellos [los padres] busquen a la pareja porque así empiezan los pleitos". Cuando se case manifestó que desea vivir en una casa diferente a la de sus padres y suegros (muchacha de 15 años, con dos apellidos mayas, su papá hace milpa y dijo no profesar ninguna religión).

- Ser joven "es muy divertido porque aprendes muchas cosas". Para ella la juventud acaba: "cuando se casan y tienen hijos". Espera del futuro: "tener muchas oportunidades de trabajo y ser feliz". Cree en el amor y piensa casarse "porque siempre he considerado tener una familia muy feliz". Para ello cree en el noviazgo porque "a travez de eso se vasa tu felicidad". De su pareja espera "Amor, cariño, confianza, diversión y felicidad", y en cambio no aceptaría de él: "ser rencoroso, tener vicios y no tener confianza". Sobre la posibilidad de que sus padres elijan a su pareja ella cree: "que sería muy incómodo porque tal vez no llegara a ser feliz", aunque al casarse sí aceptará vivir con sus suegros (muchacha de 15 años, dos apellidos mayas, su padre no hace milpa y es católica).

- Ser joven es "vivir al 100\%, es la mejor etapa". Ella se considera joven "porque tengo 16 años y vivo mi vida al máximo", y piensa que esa etapa "termina cuando ya eres adulto". Del futuro espera "que cambien algunas cosas, que deje de existir las drogas". Ella no cree en el amor, pero sí piensa casarse. Considera que el noviazgo es importante porque "se pueden conocer más antes de casarse". De su pareja espera: "Que me quiera, que me ame y que me tenga confianza". En cambio, de él no aceptaría "que se drogue y que tome cerveza diarios, y que no tenga confianza". Ella piensa que sí aceptaría que sus padres escogieran a su pareja porque "a veces [los padres] tienen razón de que tu pareja sea un buen hombre trabajador". Sin embargo, al casarse ella desearía vivir en una casa aparte, diferente a la de los padres y suegros (muchacha de 16 años, tiene un apellido maya, su papá hace milpa y no especificó profesar alguna religión).

- Ser joven es: "Una oportunidad para disfrutar la vida, disfrutar a lo sano, una oportunidad para empezar a comprender la vida", aunque ella piensa que "no se deja de ser joven". Espera del futuro: "Muchas cosas, tener una buena familia, ser alguien en esta vida". Cree en el amor y espera casarse, para lo cual piensa que el noviazgo es importante "porque así las parejas se conocen y saben como son". En una pareja busca "fidelidad, amor, cariño y comprensión", aunque no aceptaría de ella la "infidelidad y la mentira". Cree que los padres podrían tener razón en escoger a su pareja "pues los padres saben lo que hacen y dicen", aunque al casarse ella preferirá vivir de forma independiente (muchacha, 16 años, un apellido maya, su papá hace milpa y no indicó profesar alguna religión). 
— "Ser joven significa una etapa más de mi vida y ser un joven es algo lindo". "Se empieza a los 15 años y se termina a los 35". "Yo espero tener en el futuro un título de maestra". Ella no cree en el amor y no tiene la intención de casarse "porque por ahora pienso que todos los hombres son malos y no quisiera que me maltraten". Sin embargo, considera que el noviazgo es importante "porque así vas conociendo a tu pareja". Ella dice: "Yo busco a un hombre amoroso, respetuoso y comprensivo", y de éste no aceptaría "que tenga hijos con otra y que me regañe". En cuanto a que los padres puedan decidir sobre su pareja, dice: "Pienso que es algo mal porque ellos no deben decidir sobre mi ya que yo voy a estar con el y no ellos". En consecuencia, si llegara a casarse, ella preferiría vivir en una casa independiente (muchacha, 15 años, un apellido maya, su papá hace milpa y es católica).

Como se aprecia, la elección libre de la pareja es uno de los cambios más significativos en la vida de las muchachas y se asocia con su derecho a estudiar y a ser jóvenes. Por otra parte, si bien la tendencia a rechazar el matrimonio arreglado por los padres ya venía desde la generación anterior, es ahora, entre las actuales muchachas, cuando el tema ha llegado a considerarse como un problema de rebeldía, sobre todo porque incluye su rechazo a vivir con sus suegros durante los primeros años de matrimonio, como lo indican las formas tradicionales.

En consecuencia con la idea prevaleciente del amor y la felicidad como componentes importantes de la vida actual, las muchachas exigen cambios profundos en los criterios de elección de su pareja, entre los que destacan que no tome alcohol, que las respeten en sus decisiones y que no se ejerza ningún tipo de violencia sobre ellas. Además, se oponen a la tradición que les señala como único futuro posible el matrimonio, ser buenas esposas y madres. Así, las muchachas, sin anular la opción del matrimonio, esperan trabajar como maestras (7), guías de turistas (3), empresarias (2), abogadas (2), amas de casa (2), secretarias (1), chefs (1), enfermeras (1) o arquitectas (1), por lo que tienen nuevas expectativas para sus vidas.

\section{Reflexiones finales}

Hasta aquí he efectuado una breve presentación de lo que significa ser mujer y ser joven entre las muchachas mayas de un pueblo de Yucatán. He mostrado cómo sobre ciertos referentes culturales y en nuevos contextos de socialización - como la escuela - las nuevas generaciones están reelaborando sus significados tradicionales en la cultura maya, e incluso generando nuevas prácticas sociales, algunas de ellas valoradas negativamente por los adultos, ya que cuestionan la autoridad de estos últimos y lo que ellos consideran correcto.

En este recorrido he mostrado la importancia de recurrir a la historia, la lingüística y la etnografía para analizar la historicidad de la presencia de los jóvenes indígenas, en este caso para demostrar su presencia desde la época prehispánica, lo que aporta elementos para discutir la idea ampliamente difundida de que entre los indígenas la juventud ha sido producto exclusivo de la modernidad. De igual manera, me he referido a cómo dichas disciplinas son fundamentales para comprender lo que significa ser mujer y ser joven en la cultura maya a lo largo del tiempo. Además, recurrí a cuestionarios para conocer, desde sus propias palabras, lo que piensan las muchachas sobre su identidad como jóvenes y sobre sus expectativas de futuro.

Este ejercicio se presenta como un paso en la construcción de una metodología que abone a la investigación de los jóvenes en pueblos indígenas contemporáneos, entre cuyos retos se encuentran el diálogo inter y transdisciplinario para recuperar los contextos históricos, lingüísticos, familiares, sociales y culturales implicados en la construcción social del género y de la juventud en contextos étnicos, para de esa forma advertir tanto las continuidades como los significados cambiantes de ser mujer y ser joven dentro de un contexto cultural e histórico particular. 


\section{Notas}

${ }^{1}$ El 19 de noviembre de ese año se aplicó un cuestionario entre los estudiantes del Colegio de Bachilleres de Yucatán (COBAY). De un total de 80 jóvenes de entre 15 y 18 años inscritos en el primer año, 52 fueron hombres y 28 mujeres. La cantidad menor de mujeres se debe a que ellas, en relación con los hombres, se inscriben en menor número. La intención fue privilegiar la narrativa peculiar y significativa de algunas muchachas, Se brindan testimonios que no se explicitaron en el libro Ser joven y ser maya (Pérez Ruiz, 2015), donde fueron codificados y procesados para elaborar el análisis cuantitativo y comparativo entre muchachas y muchachos.

${ }^{2}$ Existe un debate sobre si la cultura maya es resultado de la dualidad como oposición o de dualismo como complementariedad. Esta especificidad desborda los objetivos de este trabajo. Una introducción al tema en Mesoamérica puede consultarse en López Austin (1996) y, entre los mayas yucatecos, en Álvarez (1997).

${ }^{3}$ Comunicación personal, marzo de 2016.

${ }^{4}$ En la etnografía sobre los mayas de Chiapas, por ejemplo, Collier (1980) en Zinacantán, Chiapas, plantea que el noviazgo es un período de ajuste, una transición de la infancia a la edad adulta para la joven pareja que habrá de casarse. Vista como un todo, la complejidad del ritual, que involucra a los familiares de la pareja, tiene como fin que ésta última se mantenga rodeada de personas interesadas en que ese matrimonio sea un éxito. La autora supone que el hecho de que el noviazgo sea una transacción económica es fundamental para que el matrimonio tenga éxito, ya que todas las partes implicadas han invertido mucho dinero en él mediante complejos rituales que involucran el intercambio de bienes y recursos.

${ }^{5}$ Diversos estudios sobre la migración con enfoque de género muestran las transformaciones que sufren las relaciones familiares de comunidades rurales e indígenas, ya sea cuando es la mujer quien sale a trabajar o cuando ésta debe quedarse bajo la tutela de la suegra. Por ejemplo, D’Aubeterre $(1999,2002)$ muestra las tensiones que provoca la migración en las normas, las creencias y las representaciones colectivas de lo que socialmente se considera que son los comportamientos legítimos; Besserer (1999) analiza los "dramas sociales" que se suscitan y que, sin embargo, establecen puentes entre "el amor y la democracia" a través de la práctica de la elección de la pareja, y Rivermar (2002) ejemplifica la lucha de las mujeres jóvenes por independizarse de sus suegros, a quienes deben servir y que toman decisiones sobre su vida y la de sus hijos en ausencia de su marido.

6 Se han transcrito las palabras de las muchachas respetando su peculiar forma de escritura.

\section{Referencias bibliográficas}

Álvarez, Cristina (1997). Diccionario etnolingüístico del idioma maya yucateco colonial. 3 t. México: UNAM.

Báez-Jorge, Félix (1975). "La mujer zoque: pasado y presente". En Los zoques de Chiapas. Colección Presencias, 39. México: SEP/INI, pp. 237-274.

Bastarrachea, Juan R., Ermilo Yah Pech y Fidencio Briceño Chel (1992). Diccionario básico español-mayaespañol. Mérida: Maldonado Editores.

Besserer, Federico (1999). "Sentimientos (in)apropiados de las mujeres migrantes. Hacia una nueva ciudadanía”. En Dalia Barrera Bassols y Cristina Ohemichen Bazán (coords.), Migración y relaciones de género en México. México: IIA-UNAM/GIMTRAP, pp. 371-388.

Bracamonte y Sosa, Pedro y Gabriela Solís Robleda (1996). Espacios mayas de autonomía. El pacto colonial en Yucatán. México: Universidad Autónoma de Yucatán/ CONACyT.

Collier, Jane F. (1980). "El noviazgo zinacanteco como transacción económica”. En Evon Z. Vogt (ed.), Los zinacantecos. México: INI, pp. 235-250.

Conway, Jill K., Susan C. Bourque y Joan W. Scott (2000). "El concepto de género". En Marta Lamas (comp.), El género. La construcción cultural de la diferencia sexual. México: PUEG/Miguel Ángel Porrúa, pp. 2-6.

D’Aubeterre Buznego, María Eugenia (1999). "Mujeres y espacio social transnacional: maniobras para renegociar el vínculo conyugal". En Dalia Barrera Bassols y Cristina Ohemichen Bazán (coords.), Migración y relaciones de género en México. México: IIAUNAM/GIMTRAP, pp. 63-85. 
D’Aubeterre Buznego, María Eugenia (2002). "Migración transnacional, mujeres y reacomodos domésticos". En María da Gloria Marroni y María Eugenia D'Aubeterre (coords.), Con voz propia. Mujeres en los noventa. Puebla: Instituto de Ciencias Sociales y Humanidades-Benemérita Universidad Autónoma de Puebla, pp. 45-68.

De la Garza, Mercedes (2003). "El matrimonio, ámbito vital de la mujer maya". En Arqueología Mexicana, $\mathrm{X}(60): 30-37$.

De Landa, Diego (2001). Relación de las cosas de Yucatán. Mérida: Dante.

Feixa, Carles y Yanko González (2005). "The SocioCultural Construction of Youth in Latin America: Achievements and Failures". En H. Helve y G. Holm (eds.), Contemporary Youth Research. Local Expressions and Global Connections. Londres: Ashgate, pp. 39-47.

Giménez Montiel, Gilberto (2003). "Las diferentes formas de discriminación desde la perspectiva de la lucha por el reconocimiento". S.p.i. Disponible en: http://www.culturayrs.org.mx/seminario/ bibliografia (consultado en marzo de 2008).

Güemes Pineda, Miguel (2000). "La concepción del cuerpo humano, la maternidad y el dolor entre mujeres mayas yukatekas". En Mesoamericana, 21(39): 305-332.

Kay Vaughan, Mary (2002). “Introducción”. En María da Gloria Marroni y María Eugenia D'Aubeterre (coords.), Con voz propia. Mujeres en los noventa. México: Instituto de Ciencias Sociales y HumanidadesBenemérita Universidad Autónoma de Puebla, pp. 9-35.

López Austin, Alfredo (1996). Los mitos del tlacuache. Caminos de la mitología mesoamericana. México: IIAUNAM.

Mead, Margaret (1970). Cultura y compromiso. Estudio sobre la ruptura generacional. Buenos Aires: Granica.

Mead, Margaret (1979). Adolescencia, sexo y cultura en Samoa. Barcelona: Laia.

Oehmichen Bazán, Cristina (1999). "Las mujeres indígenas migrantes en la comunidad extraterritorial". En Dalia Barrera Bassols y Cristina Ohemichen Bazán (coords.), Migración y relaciones de género en México.
México: IIA-UNAM/GIMTRAP, pp. 321-348.

Oehmichen Bazán, Cristina (2005). Identidad, género y relaciones interétnicas. Mazahuas en la Ciudad de México. México: IIA-UNAM.

Ortner, Sherry B. y Harriet Whitehead (1991). "Indagaciones acerca de los significados sexuales". En Carmen Ramos Escandón (comp.), El género en perspectiva. De la dominación universal a la representación múltiple. México: UAM-Iztapalapa, pp. 61-112.

Pérez Ruiz, Maya Lorena (1983). Cambios en la organización social y familiar de la producción en el Ejido de Yaxcabá, Yucatán. México: Escuela Nacional de Antropología e Historia.

Pérez Ruiz, Maya Lorena (2008). Jóvenes indígenas y globalización en América Latina. México: Instituto Nacional de Antropología e Historia.

Pérez Ruiz, Maya Lorena (2015). Ser joven y ser maya en un mundo globalizado. México: Instituto Nacional de Antropología e Historia.

Ramos Escandón, Carmen (1991). "El género en perspectiva: de la dominación universal a la representación múltiple". En Carmen Ramos Escandón (comp.), El género en perspectiva. De la dominación universal a la representación múltiple. México: UAM-Iztapalapa, pp. 61-112.

Reguillo, Rossana (2000). "Organización y agregaciones juveniles. Los desafíos para la investigación”. En José A. Pérez Islas (coord.), Jóvenes: una evaluación del conocimiento. La investigación sobre juventud en México 19681999, t. II. México: Instituto Mexicano de la Juventud, pp. 517-521.

Rivermar Pérez, María Leticia (2002). "Migración y reorganización de las relaciones conyugales y familiares en una comunidad nahua”. En María da Gloria Marroni y María Eugenia D’Aubeterre (coords.), Con voz propia. Mujeres rurales en los noventa. Puebla: Instituto de Ciencias Sociales y Humanidades -Benemérita Universidad Autónoma de Puebla, pp. 69-93.

Rosado Rosado, Georgina (1999a). "De la voz a la escritura. La figura femenina en los mitos mayas". En Georgina Rosado Rosado (coord.), Mujer maya: siglos tejiendo una identidad. Mérida: CONACULTA/Fonca/ Universidad Autónoma de Yucatán, pp. 187-209. 
Rosado Rosado, Georgina (1999b). "Los etnógrafos del siglo XX y la mujer maya”. En Georgina Rosado Rosado (coord.), Mujer maya: siglos tejiendo una identidad. Mérida: CONACULTA/Fonca/Universidad Autónoma de Yucatán, pp. 71-109.

Ruz, Mario H. (2004). "De cuerpos floridos y envolturas de pecado". En Arqueología Mexicana, XI(65): 22-27.

Santana Rivas, Landy (1999). "La mujer en la sociedad maya, la ayuda idónea”. En Georgina Rosado Rosado (coord.), Mujer maya: siglos tejiendo una identidad. Mérida:
CONACULTA/Fonca/Universidad Autónoma de Yucatán, pp. 33-69.

Scott, Joan (1996). "El género: una categoría útil para el análisis histórico”. En Marta Lamas (comp.), El género: la construcción cultural de la diferencia sexual. México: PUEG-UNAM, pp. 265-302.

Urteaga Castro, Maritza (2008). "Lo juvenil en lo étnico. Migración juvenil indígena en la sociedad contemporánea mexicana". En Pontoe Vírgula.Pontificia Universidade Católica de Sao Paulo, 4: 261-275. 